\title{
PERBANDINGAN PEMAHAMAN PENCEGAHAN KARIES GIGI METODE VIDEO DAN LEAFLET SISWA PESANTREN AR-RAUDHATUL HASANAH MEDAN TAHUN 2020
}

\author{
Ameta Primasari ${ }^{1}$, Minasari $^{2}$, Filia Dana Tyasingsih ${ }^{3}$, Yendriwati $^{4}$, \\ Gilang Dewa Brata \\ Departemen Biologi Oral \\ Fakultas Kedokteran Gigi Universitas Sumatera Utara ${ }^{12345}$ \\ Email: ${ }^{5}$ gilangdewabrata@gmail.com
}

\begin{abstract}
This community service invites children to understand the counseling material provided by the author. The media used are video media and leaflets regarding the prevention of dental caries. The type of community service used is a quasi-experimental design with a pretest-posttest design. The method includes primary data and secondary data. Primary data is data directly from respondents through direct interviews using an understanding questionnaire about caries prevention. Secondary data, namely data that supports primary data obtained from records or documents of Pesantren Ar-Raudhatul Hasanah Medan. The purpose of community service is to find out the differences in understanding between men and women, then the differences in the results of the pre-test and post-test, and compare which measurement method is the best. This aspect of measurement in community service is based on respondents' answers to questions from a questionnaire that is adjusted to the score, generally composed of 15 questions. The sample in this community service consisted of 2 groups, namely 34 students who were given health counseling with video media and 34 students who were given leaflet counseling. Based on the data, the results showed that there was a significant difference between the increase in caries knowledge in children who received health education using video media and leaflets, because a p value of 0.037 was obtained.
\end{abstract}

Keywords: video method, leaflet method, caries prevention, counseling

\begin{abstract}
Abstrak
Pengabdian kepada masyarakat ini mengajak anak-anak untuk memahami materi penyuluhan yang diberikan penulis. Media yang digunakan yaitu media video dan leaflet mengenai pencegahan karies gigi. Jenis pengabdian kepada masyarakat yang digunakan adalah eksperimen semu (quasi experiment) dengan rancangan pretest-posttest design Metode mencakup data primer dan data sekunder. Data primer adalah data yang langsung dari responden melalui wawancara langsung menggunakan kuesioner pemehaman tentang pencegahan karies. Data sekunder, yaitu data yang mendukung data primer yang diperoleh dari catatan atau dokumen Pesantren Ar-Raudhatul Hasanah Medan. Tujuan pengabdian kepada masyarakat adalah mengetahui perbedaan pemahaman antara laki-laki dan perempuan, kemudian perbedaan hasil pre-test dan post-test, serta membandingkan metode pengukuran mana yang terbaik. Aspek pengukuran dalam pengabdian kepada masyarakat ini didasarkan pada jawaban responden terhadap pertanyaan dari kuesioner yang disesuaikan dengan skor, secara umum disusun sebanyak 15 pertanyaan. Berdasarkan data hasil menunjukkan bahwa ada perbedaan yang bermakna antara peningkatan pengetahuan karies pada anak yang mendapatkan pendidikan kesehatan menggunakan media video maupun leaflet, karena didapatkan nilai $p$ value sebesar 0,037 .
\end{abstract}

Kata kunci : metode video, metode leaflet, pencegahan karies, penyuluhan 


\section{Vol. 16 No.2 Mei - Agustus 2021}

\section{PENDAHULUAN}

Karies gigi merupakan penyakit multifaktorial yang kompleks melibatkan interaksi antara struktur gigi, mikroorganisme oral yang terbentuk di permukaan gigi, karbohidrat makanan, terutama gula dan sedikit pati, dan pengaruh saliva dan genetik. Pemahaman tentang karies gigi juga dikaitkan bagaimana perilaku, sosial, dan faktor psikologis dan juga bagaimana penyakit diekspresikan pada individu yang berbeda. ${ }^{1}$

Berdasarkan data Riset Kesehatan Dasar (RISKESDAS) yang dilakukan oleh Kementerian Kesehatan Indonesia pada tahun 2018 menunjukkan peningkatan pada proporsi masyarakat Indonesia yang mengalami masalah gigi dan mulut dibandingkan dengan hasil RISKESDAS tahun 2013, yaitu dari 25,9\% pada tahun 2013 menjadi 57,6 \% pada tahun $2018 .^{2}$

Salah satu cara untuk mengetahui status karies gigi adalah dengan perhitungan indeks Decay Missing Filled Teeth atau DMFT. ${ }^{6}$ Angka D (decay) adalah jumlah gigi berlubang akibat karies gigi, angka $\mathbf{M}$ (missing) adalah gigi yang dicabut akibat karies gigi, dan angka $F$ (Filled) adalah gigi yang ditumpat akibat karies gigi. ${ }^{7}$ Pengabdian kepada masyarakat pada Asia Tenggara ditemukan bahwa India, Thailand, Indonesia dan Korea adalah negara yang berisiko memiliki tingkat indeks DMF-T yang tinggi. ${ }^{3}$

Berdasarkan uraian di atas, kami tertarik mengadakan pendidikan kesehatan yang membandingkan antara dua metode yaitu metode ceramah melalui leaflet dan media video dengan judul: Perbandingan Pemahaman Tentang Pencegahan Karies Gigi
Menggunakan Metode Video Dan Leaflet Pada Anak di Pesantren Roudatul Hasanah di Medan.

\section{BAHAN DAN METODE}

Jenis pengabdian kepada masyarakat yang digunakan adalah eksperimen semu (quasi experiment) dengan rancangan pretestposttest design with one group. Kelompok yang diteliti pada design ini diambil secara nonrandomized oleh penulis sebagai kelompok yang akan diberikan perlakuan dalam pengabdian kepada masyarakatini (Notoatmodjo, 2016). Pengabdian kepada masyarakatini menggunakan perlakuan dengan media video dan leaflet. ${ }^{4}$ Rancangan pengabdian kepada masyarakat sebelum dan sesudah intervensi dengan menggunakan kelompok pembanding disajikan secara skematik. Pre-test dilakukan sebelum perlakuan. Post-Test dilakukan setelah dilakukan perlakuan (intervensi). Pre-test dilakukan sebelum perlakuan. Post-Test dilakukan 10 hari setelah perlakuan, hal ini menurut Brigham dalam Azwar, yang menyatakan bahwa orang akan masih ingat isi pesan yang disampaikan dalam waktu 10-14 hari setelah pesan itu disampaikan. ${ }^{5}$

Metode pengumpulan data dalam pengabdian kepada masyarakatini mencakup data primer dan data sekunder. Data primer adalah data yang langsung diperoleh dari responden melalui wawancara langsung menggunakan kuesioner pemehaman tentang pencegahan karies. Data sekunder, yaitu data yang mendukung data primer yang diperoleh dari catatan atau dokumen Pesantren ArRaudhatul Hasanah Medan yang terdiri dari 
gambaran umum lokasi pengabdian kepada masyarakatdan jumlah siswa.

\section{Metode Pengukuran}

Aspek pengukuran dalam pengabdian kepada masyarakatini didasarkan pada jawaban responden terhadap pertanyaan dari kuesioner yang disesuikan dengan skor yaitu:

Pengukuran pemahaman tentang pencegahan karies. Jawaban pertanyaan yang diberikan pada responden, selanjutnya dibuat dengan tiga

(3) skala pengukuran, yaitu.

a. Kategori baik apabila total nilai yang diperoleh $>75 \%$

b. Kategori sedang apabila total nilai yang diperoleh 56-75\%

c. Kategori kurang apabila nilai yang diperoleh $<56 \%$.

HASIL

$$
\text { Pada pengabdian kepada }
$$

masyarakatini, karakteristik responden yang dilihat meliputi umur dan

jenis. Tabel 4.1 menunjukkan bahwa kelompok perlakuan dengan media video berdasarkan umur sebagian besar sebanyak 20 orang $(58,8 \%)$ berada pada umur 13 tahun. Berdasarkan jenis kelamin sebagian besar responden 18 orang laki-laki $(18,2 \%)$.

Kelompok perlakuan dengan media leaflet berdasarkan umur 25 orang $(73,5 \%)$ berada pada umur 13 tahun dan sebanyak 9 orang $(26,5 \%)$ berada pada umur 12 tahun. Berdasarkan jenis kelamin responden 19 orang perempuan $(55,9 \%)$ dan sebanyak 15 orang laki-laki $(44,1 \%)$.

Tabel 4.1 Karakteristik Responden Berdasarkan Umur dan Jenis Kelamin di
Pesantren Ar-Raudhatul Hasanah Medan

Tahun 2020

\begin{tabular}{|c|c|c|c|c|c|}
\hline \multirow[t]{2}{*}{$\begin{array}{l}\mathbf{N} \\
\mathbf{0}\end{array}$} & \multirow[t]{2}{*}{$\begin{array}{l}\text { Karakter } \\
\text { istik }\end{array}$} & \multicolumn{2}{|c|}{$\begin{array}{l}\text { Kelompok } \\
\text { Perlakuan } \\
\text { Media } \\
\text { video }\end{array}$} & \multicolumn{2}{|c|}{$\begin{array}{l}\text { Kelompok } \\
\text { Perlakuan } \\
\text { Media } \\
\text { Leaflet }\end{array}$} \\
\hline & & $\begin{array}{l}\text { Juml } \\
\text { ah }\end{array}$ & $\%$ & $\begin{array}{l}\text { Juml } \\
\text { ah }\end{array}$ & $\%$ \\
\hline & $\begin{array}{l}\text { Umur } \\
12 \text { tahun } \\
13 \text { tahun } \\
14 \text { tahun }\end{array}$ & $\begin{array}{l}13 \\
20 \\
1\end{array}$ & $\begin{array}{l}38, \\
2 \\
58, \\
8 \\
3\end{array}$ & $\begin{array}{l}9 \\
25\end{array}$ & $\begin{array}{l}26, \\
5 \\
73, \\
5\end{array}$ \\
\hline & Total & 34 & $\begin{array}{l}10 \\
0\end{array}$ & 34 & $\begin{array}{l}10 \\
0\end{array}$ \\
\hline & $\begin{array}{l}\text { Jenis } \\
\text { Kelamin } \\
\text { Laki-Laki } \\
\text { Perempua } \\
\text { n }\end{array}$ & $\begin{array}{l}18 \\
16\end{array}$ & $\begin{array}{l}52, \\
9 \\
47, \\
1\end{array}$ & $\begin{array}{l}15 \\
19\end{array}$ & $\begin{array}{l}44, \\
1 \\
55, \\
9\end{array}$ \\
\hline & Total & 34 & $\begin{array}{l}10 \\
0\end{array}$ & 34 & $\begin{array}{l}10 \\
0\end{array}$ \\
\hline
\end{tabular}

Tabel 4.2 Perbedaan Pemahaman Tentang Pencegahan Karies Gigi Pada Laki-Laki dan Perempuan

\begin{tabular}{|c|c|c|c|c|c|c|c|}
\hline \multirow[t]{2}{*}{$\begin{array}{l}\mathbf{N} \\
\mathbf{0}\end{array}$} & \multirow[t]{2}{*}{$\begin{array}{l}\text { Karakt } \\
\text { eristik }\end{array}$} & \multicolumn{3}{|c|}{$\begin{array}{l}\text { Kelompok } \\
\text { Perlakuan } \\
\text { Media video }\end{array}$} & \multicolumn{2}{|c|}{$\begin{array}{l}\text { Kelomp } \\
\text { ok } \\
\text { Perlaku } \\
\text { an } \\
\text { Media } \\
\text { Leaflet } \\
\end{array}$} & \multirow[b]{2}{*}{$\mathbf{n}$} \\
\hline & & $\begin{array}{l}\text { M } \\
\text { ea } \\
\text { n }\end{array}$ & $\begin{array}{l}\text { S } \\
\text { D }\end{array}$ & $\mathbf{N}$ & $\begin{array}{l}\text { M } \\
\text { ea } \\
\mathbf{n}\end{array}$ & $\begin{array}{l}\text { S } \\
\text { D }\end{array}$ & \\
\hline & $\begin{array}{l}\text { Jenis } \\
\text { Kelami } \\
\text { n } \\
\text { Laki- } \\
\text { Laki } \\
\text { Peremp } \\
\text { uan }\end{array}$ & $\begin{array}{l}9,2 \\
5 \\
8,4 \\
4\end{array}$ & $\begin{array}{l}1, \\
29 \\
1 \\
1, \\
29 \\
4\end{array}$ & $\begin{array}{l}1 \\
8 \\
1 \\
6\end{array}$ & $\begin{array}{l}9,5 \\
3 \\
9,0\end{array}$ & $\begin{array}{l}1, \\
24 \\
6 \\
1, \\
05 \\
4\end{array}$ & $\begin{array}{l}1 \\
5 \\
1 \\
9\end{array}$ \\
\hline
\end{tabular}

Tabel 4.3 Perbedaan Pemahaman Tentang Pencegahan Karies Gigi Pada Kelompok Sebelum dan Seseudah Diberi Media video dan Media Leaflet di Pesantren ArRaudhatul Hasanah Medan Tahun 2020

\begin{tabular}{|ccll|}
\hline & & & \\
\hline Varibel Mean & & SD & n \\
\hline $\begin{array}{c}\text { Kelompok } \\
34\end{array}$ & 8,82 & & 1,336 \\
\hline
\end{tabular}




\section{Vol. 16 No.2 Mei - Agustus 2021}

\begin{tabular}{|c|c|c|}
\hline \multicolumn{3}{|c|}{ Sebelum Video } \\
\hline $\begin{array}{r}\text { Kelompok } \\
34\end{array}$ & 13,82 & 0,936 \\
\hline \multicolumn{3}{|c|}{ Sesudah Video } \\
\hline $\begin{array}{r}\text { Kelompok } \\
34\end{array}$ & 9,24 & 1,156 \\
\hline \multicolumn{3}{|c|}{ Sebelum Leaflet } \\
\hline $\begin{array}{r}\text { Kelompok } \\
34 \\
\end{array}$ & 12,59 & 1,690 \\
\hline Sesudah L & & \\
\hline
\end{tabular}

Berdasarkan tabel diatas, diketahui bahwa terdapat peningkatan nilai rata-rata (mean) pemahaman siswa pretest dan posttest pemahaman dengan video yaitu dari 8,82 menjadi 13,82 sesudah diberi perlakuan dengan media video.

Terdapat peningkatan nilai rata-rata (mean) pemahaman siswa pretest dan posttest pemahaman dengan media leaflet yaitu dari 9,24 menjadi 12,59 sesudah diberi perlakuan dengan media leaflet

\section{PEMBAHASAN}

Penggunaan media sebagai media penyuluhan kesehatan dapat diterima dengan baik oleh responden. Media ini menawarkan penyuluhan yang lebih menarik dan tidak monoton. Penyuluhan dengan video menampilkan gerak, gambar dan suara sedangkan penyuluhan dengan media cetak menampilkan tulisan dan suara penyuluh secara langsung yang membuat terkesan formal. Pada saat pelaksanaan penelitian, sebagian besar responden mempunyai keingintahuan terhadap isi video dan melihat video sampai selesai.
Berdasarkan analisis terlihat adanya peningkatan mean pada pengetahuan pencegahan karies. Peningkatan tersebut lebih besar pada kelompok sesudah diberi perlakuan dari pada kelompok yang belum diberi perlakuan. Berdasarkan pengabdian kepada masyarakat didapatkan nilai berdasarkan pengetahuan sebelum diberi media video yaitu pengetahuan baik sebesar 8,82 dan sesudah diberi media video yaitu pengetahuan baik sebesar 13,82 .

Hasil pengabdian kepada masyarakat ini senada dengan pengabdian kepada masyarakat Mulyadi (2018) bahwa ada pengaruh yang signifikan sebelum dan sesudah diberikan pendidikan kesehatan dengan media video terhadap tingkat pengetahuan mengenai perilaku hidup bersih dan sehat kader usaha kesehatan sekolah. Pendidikan kesehatan dengan media video merupakan media yang efektif dalam meningkatkan pengetahuan perilaku hidup bersih dan sehat kader usaha kesehatan sekolah di Sekolah Dasar Islam Darul Mu'minin Banjarmasin. ${ }^{6}$

Menurutnya, pengetahuan tentang pencegahan kejadian karies tersebut merupakan besarnya pengetahuan atau pemahaman tentang pengertian, sebab, gejala, faktor risiko, dan pencegahan karies gigi. Salah satu faktor yang mempengaruhi pengetahuan tentang karies gigi adalah lingkungan tempat tinggal. Lingkungan tempat tinggal yang memudahkan untuk mendapatkan informasi tentang kesehatan gigi dan mulut khususnya karies gigi lewat media massa, penyuluhan dari petugas kesehatan, dan iklan-iklan secara tidak sadar dapat meningkatkan pengetahuan ibu 
tentang kesehatan gigi dan mulut khusunya karies gigi. ${ }^{7}$

Berbagai faktor yang mungkin berpengaruh pada penyuluhan adalah penyuluh, materi yang diberikan, media penyuluhan serta sasaran yang disuluh. Materi yang disampaikan cukup menarik dilihat dari antusias responden, media pada metode ceramah pun menggunakan media video dimana peneliti mencoba memaksimalkan semua panca indra dalam pengabdian kepada masyarakatini baik penglihatan maupun pendengaran.

Pemanfaatan media video dalam pembelajaran dapat memberikan pengalaman belajar yang lebih lengkap, jelas, variatif, menarik serta menyenangkan. Secara kognitif dengan melihat media video dapat memperkuat pemahaman siswa terhadap materi sebelum dan sesudah. Pada ranah afektif, media video dapat memperkuat siswa dalam merasakan unsur emosi dan penyikapan dari pembelajaran yang efektif.

Hasil nilai pretest dan posttest pengetahuan pada kelompok leaflet dengan diberikan pendidikan kesehatan yaitu nilai ratarata pretest 9,24 dan rata- rata posttest 12,59. Terdapat perbedaan pengetahuan responden antara sebelum dan sesudah dilakukan pendidikan kesehatan media audiovisual sebesar 3,35. Hal ini menunjukkan terjadi peningkatan pengetahuan responden tentang karies gigi sebelum dan sesudah dilakukan pendidikan kesehatan. Berdasarkan data hasil pengabdian kepada masyarakatmenunjukkan bahwa ada perbedaan yang bermakna antara peningkatan pengetahuan karies gigi (selisih skor pengetahuan karies gigi sebelum dan sesudah pendidikan kesehatan) pada anak yang mendapatkan pendidikan kesehatan menggunakan media video maupun leaflet, karena didapatkan nilai $p$ value sebesar 0,037.

Hasil pengabdian kepada masyarakat ini menunjukkan nilai rata- rata pengetahuan responden kedua kelompok setelah dilakukan pendidikan kesehatan tentang karies gigi. Data hasil post-test pengetahuan tentang pencegahan karies gigi pada kelompok video di dapat nilai rata-rata skor pengetahuan sebesar 13,82 dengan standar deviasi 0,936, sedangkan pada kelompok leaflet didapat nilai rata- rata skor pengetahuan sebesar 12,59 dengan standar deviasi 1,690.

Di sisi lain dengan penggunana metode ceramah, mesikpun responden juga mengalami peningkatan nilai dari hasil pretest dan posttest, namun secara keseluruhan bahwa dengan menggunakan metode ceramah masih lebih rendah nilai yang dicapai oleh responden. Ceramah yang telah disampaikan dengan bahasa sederhana, namun siswa hanya mengandalkan indera pendengaran untuk mengkaji materi yang diperolehnya. Berbeda halnya dengan media video responden tidak hanya mengandalkan indera pendengaran, namun indera pengelihatan juga sangat berperan penting untuk membantu mengingat materi yang disampaikan.

Adanya penggunaan media video yang digunakan dalam pengabdian kepada masyarakatini, secara tidak langsung meningkatkan daya ingat responden dibandingkan denagn menggunakan metode ceramah. Penyuluh dalam menyampaikan materi pembelajaran dengan sarana media audio visual, yang disampaikan oleh penyuluh kepada responden cukup menarik dengan filmfilm pendek. Penyuluh dituntut untuk mampu 


\section{Vol. 16 No.2 Mei - Agustus 2021}

menjelaskan materi pelajaran kepada siswa secara professional. Dalam pelaksanaannya penyuluh dapat mengunakan media pembelajaran dan sumber-sumber belajar yang relevan yang berkaitan dengan kesehatan gigi.

\section{KESIMPULAN}

Berdasarkan hasil pengabdian kepada masyarakat dan pembahasan, dapat diambil kesimpulan sebagai berikut:

1. Pemahaman atau pengetahuan anak tentang pencegahan karies gigi sesudah diberikan pendidikan kesehatan dengan media video rata-rata sebesar 13,82 dan media leaflet rata-rata sebesar 12,59.

2. memiliki perbedaan pemahaman tentang pencegahan karies gigi menggunakan metode video dan leaflet antara laki-laki dengan rata-rata 9,25 dan perempuan dengan rata-rata 8,44 .

3. Metode video lebih baik daripada metode leaflet dilihat dari rata-rata skor pemahaman dengan skor signifikansi sebesar $\mathrm{P}=0.037(\mathrm{P}<0.05)$

\section{SARAN}

1. Bagi Pesantren Ar-Raudhatul Hasanah Medan hendaknya melakukan pembinaan dalam bentuk pendidikan kesehatan secara rutin dan akan lebih maksimal apabila menggunakan media pemberian informasi yang berbeda dan lebih terkini agar anak lebih menjaga kesehatan gigi anakanaknya terutama masalah pencegahan karies gigi yang masih banyak terjadi dan mampu merawat dengan baik.

2. Bagi peneliti selanjutnya diharapkan untuk dapat menggunakan metode video lebih banyak dibanding menggunakan metode leaflet.

\section{REFFRENSI}

1. FDI General Assembly Resolution. Principle of Caries Classification and Management

Matrix, 2011 (http://www.fdiworldental. org/media/11674/2011. ga.resolution.on. principle.of.caries.classification.and.man agement.matrix.pdf).

2. Riset Kesehatan Dasar (Riskesdas) (2018). Badan Pengabdian kepada masyarakatdan Pengembangan Kesehatan Kementerian RI tahun 2018.

3. Moreira R.D.S. Epidemiology of Dental Caries in the World. 2012. http://cdn.intechopen.com/pdfswm/29340.pdf. (4 September 2020)

4. Notoatmodjo, Soekidjo. Metodologi Pengabdian kepada masyarakatKesehatan. Jakarta. Rineka Cipta. 2016

5. Azwar, S. Metode Penelitian. Yogyakarta: Pustaka Pelajar. 2012.

6. Kholid, A. Promosi Kesehatan dengan Pendekatan Teori Perilaku, Media, dan Aplikasinya. Jakarta: Rajawali Pers. 2014.

7. Mubarak. Promosi Kesehatan Sebuah Pengamatan Proses Belajar Mengajar dalam Pendidikan. Jokjakarta: Graha Ilmu. 2007. 